DOI: http://doi.org/10.21698/simi.2018.ab13

\title{
PHOTOCHEMICAL DEGRADATION OF 5-FLUOROURACIL
}

Razvan Mihailescu, Petruta Oancea, Adina Raducan

Department of Physical Chemistry, Faculty of Chemistry, University of Bucharest, 4-12

Elisabeta Boulevard, Bucharest, email: razvan.mihailescu09@gmail.com, Romania

Keywords: 5-fluorouracil, pharmacokinetic model, photolysis

\section{Introduction}

First synthetized in 1956, 5-Fluorouracil (5-FU) is one of the most used antitumoral drugs targeting multiple forms of cancer such as colon, esophageal, stomach, pancreatic, breast and cervical cancer. It enters the cell by facilitated transport and there it is converted through biochemical processes into several active metabolites which inhibits thymidylate synthase activity and disrupts RNA and DNA functions. On the other hand, up to $20 \%$ of 5-FU remains unmetabolised and it is eliminated in urine. Therefore it is an environmental contaminant being present in hospital wastewaters and posing a major risk to aquatic life.

\section{Materials and methods}

The fotodegradion of 5-FU solutions was carried in a $1 \mathrm{~cm}$ quartz cuvette by exposing $3 \mathrm{~mL}$ of aqueous solutions $(0.03 \mathrm{mM}, 0.08 \mathrm{mM}$ and $0.3 \mathrm{mM})$ to a low pressure mercury vapour lamp emitting UV radiation at $254 \mathrm{~nm}$. Spectroscopic measurements were done at intervals of 3 minutes of the total irradiation time.

Absorbance spectra were acquired using a JASCO V530 spectrophotometer and fluorescence spectra were obtained using a JASCO FP-8200 fluorometer. The kinetic parameters were calculated from the changes in absorbance and fluorescence spectra.

\section{Results and conclusions}

The molecular absorption spectra (Figure 1) show the decrease of 5-FU absorbance values at $267 \mathrm{~nm}$ and the formation of a new band at $257 \mathrm{~nm}$ after 30 minutes of irradiation. Regarding this aspect we concluded that 5-FU is transformed into a normal intermediate which is degraded further away into products that do not have characteristic bands between $200-800 \mathrm{~nm}$. Furthermore, the fluorescence spectra also shows the formation of an intermediate which emits at $295 \mathrm{~nm}$ after excitation with $267 \mathrm{~nm}$ while 5-FU has an emission band at $342 \mathrm{~nm}$. 


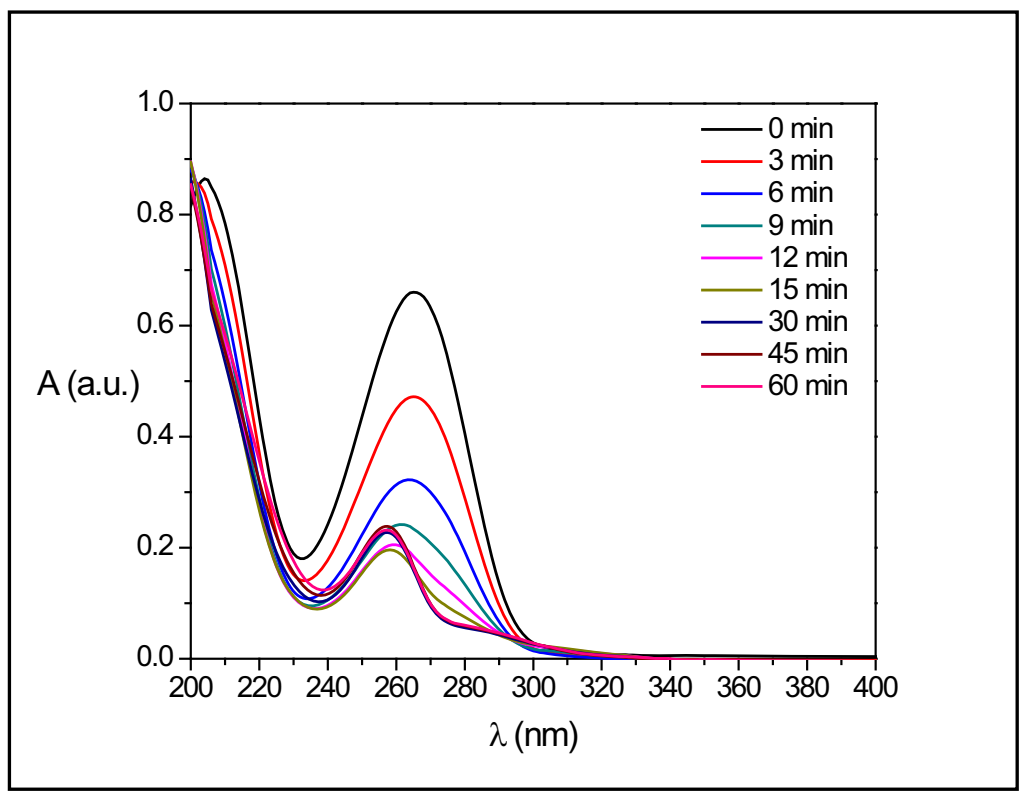

Figure 1. Absorption spectra of $[5-\mathrm{FU}]=0.08 \mathrm{mM}$ at different irradiation times

Studying the emission intensity of the intermediate in time (Figure 2) we applied the residuals method which is a model used in pharmacokinetics for oral absorption. The model assumes that on the ascending portion of the plot are taking place both formation and degradation of the intermediate, while the descending part is characterized only by degradation processes. Using exponential regression we determined the values of the formation rate constant $\left(\mathrm{k}_{1}\right)$ and the degradation constant $\left(\mathrm{k}_{2}\right)$.

From literature data we concluded that the intermediate could be an analogue of the pyrimidine uracil.

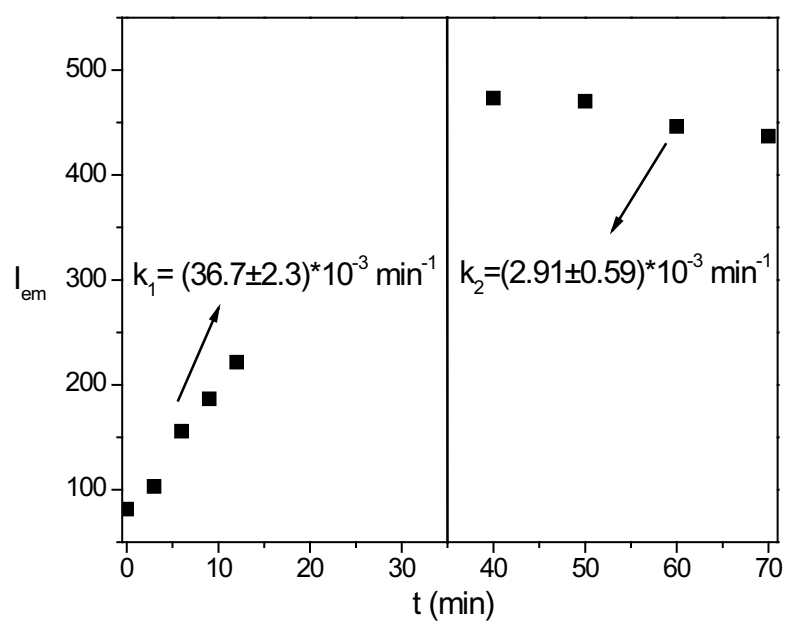

Figure 2. Intermediate emission intensity vs. time plot 